\title{
TITLE:
}

\section{Chemical Expansion of Yttrium- Doped Barium Zirconate and Correlation with Proton Concentration and Conductivity}

\section{AUTHOR(S):}

Han, Donglin; Hatada, Naoyuki; Uda, Tetsuya

\section{CITATION:}

Han, Donglin ... [et al]. Chemical Expansion of Yttrium-Doped Barium Zirconate and Correlation with Proton Concentration and Conductivity. Journal of the American Ceramic Society 2016, 99(11): 3745-3753

\section{ISSUE DATE:}

2016-11

URL:

http://hdl.handle.net/2433/236384

\section{RIGHT:}

This is the peer reviewed version of the following article: Journal of the American Ceramic Society, 99[11] 3745-3753 (2016), which has been published in final form at https://doi.org/10.1111/jace.14377. This article may be used for noncommercial purposes in accordance with Wiley Terms and Conditions for Use of Self-Archived Versions.; この論文は出 版社版でありません。引用の際には出版社版をご確認じ利用ください。;This is not the published version. Please cite only the published version. 


\section{To: Journal of the American Ceramic Society}

\section{Chemical Expansion of Yttrium-Doped Barium Zirconate and Correlation with Proton}

\section{Concentration and Conductivity}

Donglin Han ${ }^{\text {a, * }}$, Naoyuki Hatada ${ }^{\text {a }}$, Tetsuya Uda ${ }^{\text {a, * }}$

${ }^{a}$ Department of Materials Science and Engineering, Kyoto University,

Yoshida Honmachi, Sakyo-ku, Kyoto 606-8501, Japan

* Corresponding authors: Donglin Han (han.donglin.8n@kyoto-u.ac.jp)

and Tetsuya Uda (uda_lab@aqua.mtl.kyoto-u.ac.jp)

TEL: +81-75-753-5445, FAX: +81-75-753-5284 


\section{Abstract}

Y-doped $\mathrm{BaZrO}_{3}(\mathrm{BZY})$ is a promising candidate as an electrolyte in fuel cells, and attracts increasing attention. In this work, a systematic investigation was performed on microstructure, proton concentration, proton conductivity, and hydration induced chemical expansion in Y-doped $\mathrm{BaZrO}_{3}$. The results revealed that the bimodal microstructure in $\mathrm{BaZr}_{0.85} \mathrm{Y}_{0.15} \mathrm{O}_{3-\delta}$ was composed of large grains with composition close to the nominal value, and fine grains with large compositional discrepancy. This property is considered to be one of the evidences of phase separation at lower temperature than sintering temperature $\left(1600{ }^{\circ} \mathrm{C}\right)$, which hinders the grain growth. Thermal expansion coefficient of BZY was measured for various dopant level, and was determined to be around $10^{-5} \mathrm{~K}^{-1}$ in wet and dry argon atmosphere. In addition, chemical expansion effect due to hydration was confirmed by HT-XRD in dry and wet Ar atmospheres, and suggests an interesting relationship between the lattice change ratio and proton concentration, in the BZY system with different Y content. The change ratio of lattice constant due to hydration increased obviously with the proton concentration for the sample containing the $\mathrm{Y}$ content of 0.02 and 0.05 , but only changed slightly when the $\mathrm{Y}$ content was increased to 0.1 and 0.15 . However, when the $\mathrm{Y}$ content was further increased over 0.2 , the change ratio of lattice constant due to hydration starts to increase obviously again. Such results indicate a high possibility that the stable sites of protons in BZY changed with the variation in Y content.

Key words: Fuel cell; Proton conductor; Chemical expansion; Barium zirconate 


\section{Introduction}

Protonic ceramic fuel cells (PCFCs) using proton conductive oxides as electrolytes are promising devices for energy conversion, not only because of their relatively lower operation temperature range (450 - $700{ }^{\circ} \mathrm{C}$ ) enabling reduced cost on structural materials, but also an increased efficiency for fuel utilization since water vapor is produced at the cathode in PCFCs. Several candidates [1, 2] were proposed as the electrolyte in PCFCs, but barium zirconate $\left(\mathrm{BaZrO}_{3}\right)$ doped with yttrium (Y) is regarded to be the most promising one, benefitted from its high protonic conductivity $\left(>0.01 \mathrm{Scm}^{-1}\right.$ at $600{ }^{\circ} \mathrm{C}$ ) in humid atmosphere [3-6], and excellent chemical stability against $\mathrm{CO}_{2}$ and $\mathrm{H}_{2} \mathrm{O}[7,8]$. A lot of works have been dedicated to investigate fundamental properties of Y-doped $\mathrm{BaZrO}_{3}(\mathrm{BZY})$, and also its practical application in PCFCs. Recently, lattice expansion due to hydration in perovskite oxides, or hydration induced chemical expansion in another word, attracts an increasing attention [9-19], since potential risk of crack in electrolyte, or delamination between the electrolyte and electrodes during the fuel cell operation might thereby be introduced. A clear chemical expansion behavior in the BZY system was reported by Hiraiwa, et al. [12] and Andersson, et al. [16] with high temperature X-ray diffraction (HT-XRD) analysis in dry atmosphere on hydrated samples. However, much more precise information on the chemical expansion behavior should be provided through a relevant measurement in a controlled humid atmosphere, but such investigation is lacking. In addition, although fundamental properties of BZY seem to be well studied, several questions still remained. A bimodal microstructure was observed by Schober, et al. [20] in $\mathrm{BaZr}_{0.9} \mathrm{Y}_{0.1} \mathrm{O}_{3-\delta}$ 
prepared by solid state reaction method. Lately, Imashuku, et al. also reported such bimodal microstructure in $\mathrm{BaZr}_{0.85} \mathrm{Y}_{0.15} \mathrm{O}_{3-\delta}$ [21]. However, other information, such as local composition of such bimodal microstructure, has not been reported.

In this work, $\mathrm{BaZrO}_{3}$ doped with various $\mathrm{Y}$ content were prepared, and HT-XRD were performed in dry and wet Ar atmospheres to evaluate the hydration induced chemical expansion effect. Then, water content and conductivity were measured to enable a combined discussion on the correlation among these properties. In addition, energy dispersion spectroscopy equipped with a scanning transmission electron microscope (STEM-EDS) was applied to examine local composition of $\mathrm{BaZr}_{0.85} \mathrm{Y}_{0.15} \mathrm{O}_{3-\delta}$ to reveal the character of the bimodal microstructure.

\section{Experimental}

\subsection{Material preparation}

$\mathrm{BaZr}_{1-x} \mathrm{Y}_{x} \mathrm{O}_{3-\delta}(x=0.02,0.05,0.1,0.15,0.2,0.25$, and 0.3$)$ and undoped $\mathrm{BaZrO}_{3}$ were prepared by a conventional solid state reaction method. Starting materials of $\mathrm{BaCO}_{3}, \mathrm{ZrO}_{2}$, and $\mathrm{Y}_{2} \mathrm{O}_{3}$ powders were mixed at the desired ratios, and ball-milled for $24 \mathrm{~h}$. Mixtures were pelletized under $9.8 \mathrm{MPa}$ and heat-treated at $1000{ }^{\circ} \mathrm{C}$ for $10 \mathrm{~h}$. The pellets were then pulverized by a mortar, and subjected to ball-milling for $10 \mathrm{~h}$ for further pulverizing and mixing. After that, the samples were pelletized under 9.8 MPa again, and kept at $1300{ }^{\circ} \mathrm{C}$ for $10 \mathrm{~h}$ for synthesizing. The samples were pulverized by the mortar, and ball-milled for $50 \mathrm{~h}$, and subsequently mixed with a binder (NCB-166, DIC 
Corporation, Tokyo, Japan). The mixtures were then pressed into pellets at $392 \mathrm{MPa}$, and heat-treated at $600{ }^{\circ} \mathrm{C}$ for $8 \mathrm{~h}$ to remove the binder. At last, after being buried in sacrificial powders which are mixtures of the relevant synthesized powders (99 wt\%) and $\mathrm{BaCO}_{3}(1 \mathrm{wt} \%)$, the pellet-like samples were heated at $1600{ }^{\circ} \mathrm{C}$ for $24 \mathrm{~h}$ in oxygen atmosphere for sintering.

\subsection{Characterization}

Chemical compositions were determined by inductively coupled plasma atomic emission spectroscopy (ICP-AES) with SPS4000 (Seiko Instruments Inc., Chiba, Japan). Relative density of the sintered pellet-like samples was estimated with Archimedes method. Crystal structure was identified with X-ray diffraction (XRD) analysis using $\mathrm{Cu} K \alpha$ radiation with X'Pert-ProMPD (PANalytical, Almelo, Netherland). High temperature XRD (HT-XRD) measurements were performed with the same XRD device using a HTK 1200N high-temperature chamber (Anton Paar, Graz, Austria). Dry or wet $\left(p_{\mathrm{H}_{2} \mathrm{O}}=0.031 \mathrm{~atm}\right)$ argon gas was flowed in the high-temperature chamber. HT-XRD patterns were collected during cooling from 1000 to $30{ }^{\circ} \mathrm{C}$ at an average cooling rate about $1.06{ }^{\circ} \mathrm{Cmin}^{-1}$. Detailed procedures of HT-XRD measurements were described in our previous work. [12] Rietveld refinement was carried out utilizing a commercial software X’Pert HighScore Plus to determine lattice constants. Microstructures were observed by scanning electron microscopy (SEM) and scanning transmission electron microscopy (STEM) with VE-7800 (Keyence Co., Osaka, Japan) and JEM-2100F (JEOL, Tokyo, Japan), respectively. Samples for 
STEM observations were thinned by an argon ion $\left(\mathrm{Ar}^{+}\right)$beam using a JEOL EM-09100IS Ion Slicer.

The local composition was identified by STEM with JEOL JED-2300.

Karl-Fischer titration method was applied to determine water content. The pellet-like samples heat-treated at $1600{ }^{\circ} \mathrm{C}$ for sintering were broken into pieces about $2 \mathrm{~mm}$ in length, and hydrated in wet Ar with a water partial pressure of 0.05 atm for at least 6 days at desired temperature. Readers are referred to our previous works [22] for detailed procedures.

Conductivity measurements of the pellet-like samples with sputtered platinum (Pt) electrodes were performed in wet $\mathrm{H}_{2}$ atmosphere with water partial pressure kept as $0.05 \mathrm{~atm}$. Contributions of bulk (intra-grain) and grain boundary conduction was determined from the impedance spectra, which were collected by A. C. impedance spectroscopy in the frequency range from $10 \mathrm{~Hz}$ to $7 \mathrm{MHz}$ using a frequency response analyzer (Solartron SI 1260, Solartron Analytical, Farnborough, UK) with applied voltage of $100 \mathrm{mV}$ at temperature from 600 to $100{ }^{\circ} \mathrm{C}$.

\section{Results}

\subsection{Phase identification and microstructure observation}

All the samples show single perovskite phases after sintering at $1600{ }^{\circ} \mathrm{C}$ (see Fig. S1 for XRD patterns), in agreement with previous reports [23, 24]. The actual chemical compositions determined by ICP-AES were close to the nominal ones, as given in Table 1. In the following text, the samples of $\mathrm{BaZr}_{1-x} \mathrm{Y}_{x} \mathrm{O}_{3-\delta}$ will be named as the abbreviations given in the table, e. $g$., $\mathrm{BZY} 20$ for 
$\mathrm{BaZr}_{0.8} \mathrm{Y}_{0.2} \mathrm{O}_{3-\delta}$.

From SEM images of the fractured cross-section shown in Fig. 1, it is clear that a bimodal microstructure as a mixture of large and fine grains formed, when the $\mathrm{Y}$ content was $0.05,0.1$ and 0.15. Such microstructure was also confirmed from STEM observation on $\mathrm{BaZr}_{0.85} \mathrm{Y}_{0.15} \mathrm{O}_{3-\delta}$ (BZY15), as shown in Fig. 2. But, with the Y content increased over 0.2, the grain size turned to be relatively uniform.

Then, STEM-EDS point analysis was applied on BZY15 to determine the local compositions of individual grains. Since the spot size is about $1 \mathrm{~nm}$, the local compositions of the fine grains can also be determined precisely. As shown in Fig. 3(a), the large grains have the composition very close to the nominal value. However, an obvious discrepancy in composition was confirmed for the fine grains (Fig. 3(b)) (an example for STEM-EDS analysis is given in supplementary information). It seems that such bimodal structure cannot be treated simply as a mixture of grains just with different size, the difference in compositional homogeneity of the large and fine grains is another important characteristic.

\subsection{Proton concentration}

The samples hydrated at 300 and $600{ }^{\circ} \mathrm{C}$ in wet $\operatorname{Ar}\left(p_{\mathrm{H}_{2} \mathrm{O}}=0.05\right.$ atm $)$ were subjected to Karl-Fischer titration to determine the proton concentration with the results shown in Fig. $\mathbf{4}$. In general, the proton concentration increased with the increasing $\mathrm{Y}$ content. It is because that as 
given in eqn (1), increasing the $\mathrm{Y}$ content resulted in an increasing in oxide ion vacancies $\left(\mathrm{V}_{\mathrm{O}}^{*}\right)$, which benefit the hydration reaction (eqn (2)) to introduce protons $\left(\mathrm{OH}_{\mathrm{O}}^{\circ}\right)$.

$$
\begin{gathered}
\mathrm{Y}_{2} \mathrm{O}_{3}+\mathrm{Zr}_{\mathrm{Zr}}^{\times}+\mathrm{O}_{\mathrm{O}}^{\times} \rightarrow \mathrm{Y}_{\mathrm{Zr}}^{\prime}+\mathrm{ZrO}_{2}+\mathrm{V}_{\mathrm{O}}^{*} \\
\mathrm{H}_{2} \mathrm{O}+\mathrm{V}_{\mathrm{O}}^{*}=2 \mathrm{OH}_{\mathrm{O}}^{\circ}
\end{gathered}
$$

\subsection{Thermal and Chemical expansion}

Variation of lattice constants, which were determined by Rietveld refinement on the XRD patterns collected through HT-XRD measurements in dry and wet $\operatorname{Ar}\left(p_{\mathrm{H}_{2} \mathrm{O}}=0.031 \mathrm{~atm}\right)$, against the temperature is shown in Fig. 5. Here, only a single cubic perovskite ( $P m \overline{3} m$ ) model [25] was used to determine the lattice constant. For the samples with a bimodal microstructure, the fitting results should reflect an average effect from the stoichiometric large grains and fine grains with compositional discrepancy. For the samples doped with $\mathrm{Y}$, the lattice constants in wet Ar are larger than those in dry Ar, indicating an expansion effect on lattice volume due to hydration. However, since the dry Ar atmosphere in our apparatus is not absolutely free of water vapour, the Y-doped samples are hydrated slightly during cooling in the low temperature range $\left(30-400{ }^{\circ} \mathrm{C}\right)$, and their lattice constants show a positive deviation from the predicted tendency (broken lines in Fig. 4) obtained by extrapolating the data in the high temperature range $\left(700-1000{ }^{\circ} \mathrm{C}\right)$.

Then, thermal expansion coefficients (TECs) of the dehydrated samples in the dry Ar atmosphere were estimated along the broken lines in Fig. 5, with the results listed in Table 1. TEC for the 
undoped $\mathrm{BaZrO}_{3}$ is estimated to be $8.02 \times 10^{-6} \mathrm{~K}^{-1}$ in this work, and seems to increase gradually with the increasing Y content. But the case in wet Ar is a little complicated, since in addition to the thermal expansion effect, the chemical expansion induced by the hydration reaction (eqn (2)) also plays a very important role [16]. But in the relatively low temperature range $\left(\right.$ e.g., $\left.<300{ }^{\circ} \mathrm{C}\right)$ where the variation of the amount of water molecules incorporated into BZY with the temperature is negligibly small $[5,26,27]$, the change of the lattice constant in wet Ar is almost parallel with that in dry Ar. It means that if excluding the effect from chemical expansion, the value of TEC in wet and dry Ar is very close.

The lattice constants in dry and wet Ar at 300 and $600{ }^{\circ} \mathrm{C}$ are summarized in Fig. 6 (data at $30{ }^{\circ} \mathrm{C}$ are given in Fig. S3), together with the change ratio of lattice constant, which is defined by eqn (3), to give a quantitative evaluation of the chemical expansion effect [19]. In eqn (3), $a_{\mathrm{wet}} \mathrm{Ar}$ and $a_{\mathrm{dry}} \mathrm{Ar}$ are the lattice constants at 300 or $600{ }^{\circ} \mathrm{C}$ obtained in wet and dry Ar atmospheres, respectively. The extrapolated lattice constants in dry Ar were used here. It can be seen that the change ratio of lattice constant due to hydration exhibits a tendency to increase with the increasing $\mathrm{Y}$ content, indicating an enhanced chemical expansion effect.

$$
\text { Change ratio of lattice constant }=\frac{a_{\text {wet Ar }}-a_{\text {dry Ar }}}{a_{\text {dry Ar }}} \times 100 \%
$$

Deep insight into the behaviour of protons in the crystal lattice of BZY might be provided by exploring the relationship between the proton concentration and the change ratio of lattice constant. As shown in Fig. 7, when the Y content was very low (0.02 and 0.05), the change ratio of lattice 
constant shows an obvious tendency to increase with the increasing proton concentration. However,

a plateau appeared when the $\mathrm{Y}$ content was between 0.05 and 0.15 , that is; although the proton concentrations still increased, the change ratio of lattice constant increased only a little. When the Y content was further increased over 0.2 , the change ratio of lattice constant turned to increase significantly again with the increasing proton concentration. This phenomenon is quite interesting. Such special behaviour implies that it is not a simple proportional relation between the degree of chemical expansion effect and the proton concentration. Some other factors also play important roles.

\subsection{Bulk and grain boundary conductivities}

By analyzing the electrochemical impedance spectra collected in wet $\mathrm{H}_{2}$, contributions belonging to bulk (intra-grain) and grain boundary conductions are separated [5, 19]. Arrhenius plots of the bulk and grain boundary conductivities of $\mathrm{BaZrO}_{3}$ doped with various $\mathrm{Y}$ content are shown in Fig. 8 and

Fig. 9, respectively. Here, the bulk and grain boundary conductivities were calculated following eqn. (4). $\quad \sigma$ is the conductivity. $\quad L$ and $S$ are the thickness and surface area of the pellet-like sample for impedance measurement, respectively. $\quad R$ is the resistance belonging to bulk or grain boundary determined from impedance spectra.

$$
\sigma=\frac{L}{R \times S}
$$

The contribution from bulk conduction can only be separated at relatively low temperature (an 
example of BZY25 is given in the supplementary information). We here only plotted the bulk and grain boundary conductivities at $300{ }^{\circ} \mathrm{C}$ in Fig. 10 for comparison. The bulk conductivity is very low for the sample with the Y content of 0.02 and 0.05 . But, when the Y content was increased from 0.05 to 0.1 , the bulk conductivity increased dramatically from $0.61 \mathrm{mScm}^{-1}$ (BZY5) to 2.66 $\mathrm{mScm}^{-1}$ (BZY10). It means that the $\mathrm{Y}$ content is just doubled, but the proton conductivity increased by more than four times. However, further increasing the $\mathrm{Y}$ content over 0.1 does not result in a large change in the proton conductivity. Referring to the grain boundary conductivity, it increased slightly with Y content from 0.02 to 0.15 , but a dramatic increase occurred when the Y content was elevated from 0.15 to 0.2 . Further increase in the $\mathrm{Y}$ content results in a decrease in the grain boundary conductivity. Apparently, $\mathrm{BaZr}_{0.8} \mathrm{Y}_{0.2} \mathrm{O}_{3-\delta}$ possess the highest value.

The activation energy $\left(E_{\mathrm{a}}\right)$ and pre-exponential factor $(A)$ of the bulk conduction were extracted by fitting the conductivity data collected between 100 and $200{ }^{\circ} \mathrm{C}$ following eqn. (5). Here, $T$ is temperature and $k_{\mathrm{B}}$ is Boltzmann's constant.

$$
\sigma T=A \exp \left(\frac{-E_{\mathrm{a}}}{k_{\mathrm{B}} T}\right)
$$

Some literature data with their experimental conditions summarized in Table 2 were also plotted for comparison in Fig. 11. Our results agree well with that reported by Bohn, et al [28], Imashuku, et al [21], and Yamazaki, et al [29], but higher than those reported by Fabbri, et al., [23] with a higher fitting temperature range of $350-500{ }^{\circ} \mathrm{C}$. As shown in Fig. 11(a), the activation energy of bulk conduction shows a tendency to increase with the increasing Y content. And the pre-exponential 
factor, as shown in Fig. 11(b), increased when the $\mathrm{Y}$ content was increased from 0.02 to 0.1 , but changed slightly when the $\mathrm{Y}$ content was further increased. (The activation energy and pre-exponential factor of the grain boundary conduction are also calculated, and given in supplemental information.)

\subsection{Total conductivity}

The Arrhenius plots of the total conductivities of $\mathrm{BaZrO}_{3}$ doped with various $\mathrm{Y}$ content are shown in

Fig. 12. For the sake of comparison, Fig. 13 summarized the value at 400,500 and $600{ }^{\circ} \mathrm{C}$. It is clear that the total conductivity increased with increasing Y content from 0.02 to 0.2 , but decreased when the Y content was higher than 0.2. And $\mathrm{BaZr}_{0.8} \mathrm{Y}_{0.2} \mathrm{O}_{3-\delta}$ has the highest total conductivity at all these three temperatures compared with the other samples containing different $\mathrm{Y}$ content. Especially, the value obtained at 500 and $600{ }^{\circ} \mathrm{C}$ is larger than $0.01 \mathrm{Scm}^{-1}$, which is necessary for the application as an electrolyte in fuel cells [30].

In order to check the reproducibility of the total conductivity of $\mathrm{BaZr}_{0.8} \mathrm{Y}_{0.2} \mathrm{O}_{3-\delta}$, five different batches of BZY20 samples were prepared, and their total conductivities are shown in Fig. 14. The data marked with the circle symbols are the same as those used in Fig. 12. Although a little fluctuation appeared among different preparation batches, in general, reasonably good reproducibility was achieved. And the average value of these five different batches were calculated to be $0.0145 \pm 0.0012 \mathrm{Scm}^{-1}$ at $600{ }^{\circ} \mathrm{C}$. 


\section{Discussion}

Compared with BZY20, the grain boundary conductivity of $\mathrm{BaZr}_{1-x} \mathrm{Y}_{x} \mathrm{O}_{3-\delta}(x=0.05,0.1$ and 0.15$)$ is quite low. Relatively smaller grain size of these samples should be a reason, since the area of grain boundary thereby greatly increased. That is, it is reasonable to consider that the bimodal microstructure impacts a negative influence on the grain boundary conductivity. The bimodal microstructure of BZY15 contains the large grains with the composition close to the nominal one, and fine grains possessing significant imhomogeneity in composition. As far as we know, it is the first time that the precise local composition of such microstructure was determined. In our previous work [31], we found that when the sintering time at $1600{ }^{\circ} \mathrm{C}$ was increased from $24 \mathrm{~h}$ to $100 \mathrm{~h}$, the microstructure of BZY15 turned to be homogeneous. In addition, by using fine BZY15 powders, which can be prepared with a nitrate freeze drying method [32], even the sintering time at $1600{ }^{\circ} \mathrm{C}$ was shorten to $4 \mathrm{~h}$, a homogeneous microstructure can be achieved. These results indicate that the equilibrated status of the composition of $\mathrm{BaZr}_{0.85} \mathrm{Y}_{0.15} \mathrm{O}_{3-\delta}$ is a single perovskite phase at $1600{ }^{\circ} \mathrm{C}$. Reports on phase observation of $\mathrm{BaZr}_{0.9} \mathrm{Y}_{0.1} \mathrm{O}_{3-\delta}$ (BZY10), which also exhibited a bimodal microstructure in this work, might be informative [33, 34]. Azad, et al., [33] observed $\alpha$-BZY10 phase at relatively low temperature $\left(1500{ }^{\circ} \mathrm{C}\right)$, which changed to $\beta$-BZY10 phase when the sintering temperature elevated to $1720{ }^{\circ} \mathrm{C}$. The difference in phase behavior at lower and higher temperature possibly hinders the grain growth, and results in such bimodal microstructure. But, we do not have direct evidence of the hypothesis, and further investigation in future is needed. 
Fundamental aspect on the mechanism of proton conduction is always an important and interesting topic. A definite trapping effect of protons in BZY was recently reported by Yamazaki, et al. [35] at relatively low temperature (for example, $100-200{ }^{\circ} \mathrm{C}$ ). Briefly speaking, protons are trapped at the oxide ions near the $\mathrm{Y}$ dopant cations, but relatively free at the oxide ions close to the $\mathrm{Zr}$ host cations. In the present study, when the $\mathrm{Y}$ content is in the range between 0.02 and 0.1 , both the activation energy and the pre-exponential factor increased with the increasing Y content. Such behavior of activation energy and pre-exponential factor is reasonable, if we consider the increase of proton concentration and assume a transition status of protons at these temperature ranges, where dominant status of protons is changing from trapped ones to free ones. However, when the $\mathrm{Y}$ content is increased over 0.1, although the activation still increases with the increasing Y content, the change in pre-exponential factor is quite small. These results indicate that a simple trapping theory might be available for the system with low $\mathrm{Y}$ content $(0.02-0.1$ in this work). For the system containing high Y content, the case seems to be sophisticated rather than a simple trapping effect.

A clear dependence of the chemical expansion behavior on the Y content, which can be divided into three regions, was observed in this study (Fig. 7). Since the chemical expansion here is induced by hydration, behavior of protons in the crystal lattice of BZY is expected to be one of the main factors influencing the chemical expansion effect. A recent work by Oikawa, et al. revealed a linear relationship between the lattice constant of $\mathrm{BaZr}_{0.9} \mathrm{Sc}_{0.1} \mathrm{O}_{3-\delta}$ and proton concentration [36], implying that if the stable site of protons in the lattice does not change greatly with the proton concentration, 
an increase in proton concentration should induce a linear behavior of chemical expansion. Thereby, the phenomenon observed in Fig. 7 suggests possibly different stable sites for protons in BZY with the different Y content. For example, the location of protons might be different between $\mathrm{BaZrO}_{3}$ doped with small Y content $(0.02,0.05)$ and large $\mathrm{Y}$ content $(0.15-0.3)$. However, only macroscopic information is available in the present work, establishing detail models might be an interesting topic in the future.

\section{Conclusions}

In this work, a systematic investigation on microstructure, proton concentration, proton conductivity, thermal expansion, and hydration induced chemical expansion in Y-doped $\mathrm{BaZrO}_{3}$ was performed. By STEM-EDS analysis, it was found that the bimodal microstructure in $\mathrm{BaZr}_{0.85} \mathrm{Y}_{0.15} \mathrm{O}_{3-\delta}$ is composed of large grains with composition close to the nominal value, and fine grains with large compositional discrepancy. This property is considered to be one of the evidences of phase separation at lower temperature than sintering temperature $\left(1600{ }^{\circ} \mathrm{C}\right)$, which hinders the grain growth. Behavior of thermal expansion and chemical expansion was investigated by HT-XRD analysis. The thermal expansion coefficient in dry Ar atmosphere was estimated to be $8.02 \times 10^{-6} \mathrm{~K}^{-1}$ for undoped $\mathrm{BaZrO}_{3}$, and tended to increase with the increasing Y content. For example, about $1.01 \times$ $10^{-5} \mathrm{~K}^{-1}$ for $\mathrm{BaZr}_{0.8} \mathrm{Y}_{0.2} \mathrm{O}_{3-\delta}$. In addition, an interesting relationship was observed between the proton concentration and the lattice change ratio due to the hydration induced chemical expansion, in 
the BZY system with different Y content. Such results implied a high possibility that the stable sites of protons in BZY was different between the samples with small Y content (0.02 and 0.05) and those with large Y content $(0.15-0.3)$.

\section{Acknowledgement}

This study was supported by the New Energy and Industrial Technology Development Organization (NEDO) in Japan (project code P08023). The authors also want to thank Mr. Kenji Kazumi for STEM-EDS analysis, and Dr. Masatoshi Majima at Sumitomo Electric Industries, Ltd., for valuable discussion. 


\section{References}

${ }^{1}$ T. Norby, "Solid-State Protonic Conductors: Principles, Properties, Progress and Prospects," Solid State Ionics, 125 [1-4] 1-11 (1999).

${ }^{2}$ K.D. Kreuer, “Proton-Conducting Oxides,” Annu. Rev. Mater. Res., 33 [1] 333-59 (2003).

3 Y. Yamazaki, R. Hernandez-Sanchez, and S.M. Haile, "High Total Proton Conductivity in Large-Grained Yttrium-Doped Barium Zirconate,” Chem. Mater., 21 [13] 2755-62 (2009).

${ }^{4}$ D. Pergolesi, E. Fabbri, A. D’Epifanio, E.D. Bartolomeo, A. Tebano, S. Sanna, S. Licoccia, G. Balestrino, and E. Traversa, "High Proton Conduction in Grain-Boundary-Free Yttrium-Doped Barium Zirconate Films Grown by Pulsed Laser Deposition,” Nat. Mater., 9 [10] 846-52 (2010).

${ }^{5}$ D. Han, Y. Nose, K. Shinoda, and T. Uda, "Site Selectivity of Dopants in $\mathrm{BaZr}_{1-y} \mathrm{M}_{y} \mathrm{O}_{3-\delta}(\mathrm{M}=\mathrm{Sc}, \mathrm{Y}$, Sm, Eu, Dy) and Measurement of Their Water Contents and Conductivities,” Solid State Ionics, 213 2-7 (2013).

${ }^{6}$ D. Han, N. Hatada, and T. Uda, “Microstructure, Proton Concentration and Proton Conductivity of Barium Zirconate Doped with Ho, Er, Tm and Yb,” J. Electrochem. Soc., 163[6] F470-6 (2016).

${ }^{7}$ K. Katahira, Y. Kohchi, T. Shimura, and H. Iwahara, "Protonic Conduction in Zr-substituted $\mathrm{BaCeO}_{3}, ”$ Solid State Ionics, 138 [1-2] 91-8 (2000).

${ }^{8}$ Y. Guo, Y. Lin, H. Shi, R. Ran, and Z. Shao, “A High Electrochemical Performance Proton Conductor Electrolyte with $\mathrm{CO}_{2}$ Tolerance,” Chin. J. Catal., 30 [6] 479-81 (2009).

${ }^{9}$ S. Yamaguchi, and N. Yamada, “Thermal Lattice Expansion Behavior of Yb-doped BaCeO 3 ,” Solid 
State Ionics, 162-163 23-9 (2003).

10 J. Wu, R.A. Davies, M.S. Islam, and S.M. Haile, “Atomistic Study of Doped $\mathrm{BaCeO}_{3}$ : Dopant Site-Selectivity and Cation Nonstoichiometry,” Chem. Mater., 17 [4] 846-51 (2005).

${ }^{11}$ F. G. Kinyanjui, S. T. Norberg, I. Ahmed, S. G. Eriksson, and S. Hull, "In-situ Conductivity and Hydration Studied of Proton Conductors Using Neutron Powder Diffraction,” Solid State Ionic, 225 312-6 (2012).

12 C. Hiraiwa, D. Han, A. Kuramitsu, A. Kuwabara, H. Takeuchi, M. Majima, and T. Uda, “Chemical Expansion and Change in Lattice Constant of Y-Doped $\mathrm{BaZrO}_{3}$ by Hydration / Dehydration Reaction and Final Heat-Treating Temperature,” J. Am. Ceram. Soc., 96 [3] 879-84 (2013).

13 D. Han, M. Majima, and T. Uda, "Structure Analysis of $\mathrm{BaCe}_{0.8} \mathrm{Y}_{0.2} \mathrm{O}_{3-\delta}$ in Dry and Wet Atmospheres by High-Temperature X-ray Diffraction Measurement,” J. Solid State Chem., 205 $122-128$ (2013).

${ }^{14}$ D. Han, K. Shinoda, and T. Uda, "Dopant Site Occupancy and Chemical Expansion in Rare Earth-Doped Barium Zirconate,” J. Am. Ceram. Soc., 97 [2] 643-50 (2014).

15 D. Han, K. Kojima, M. Majima, and T. Uda, "Synthesis and Conductivity Measurement of Lanthanum Zirconate Doped with Rare Earth Dopants,” J. Electrochem. Soc., 161 [10] F977-82 (2014).

16 A.K.E. Andersson, S.M. Selbach, C.S. Knee, and T. Grande, "Chemical Expansion Due to 
Hydration of Proton-Conducting Perovskite Oxide Ceramics,” J. Am. Ceram. Soc., 97 [8] 2654-61 (2014).

17 E. Jedvik, A. Lindman, M. Benediktsson, and G. Wahnström, "Size and Shape of Oxygen Vacancies and Protons in Acceptor-Doped Barium Zirconate,” Solid State Ionics, 275 2-8 (2015).

${ }^{18}$ A.K.E. Andersson, S.M. Selbach, T. Grande, and C.S. Knee, "Thermal Evolution of the Crystal Structure of Proton Conducting $\mathrm{BaCe}_{0.8} \mathrm{Y}_{0.2} \mathrm{O}_{3-\delta}$ from High-Resolution Neutron Diffraction in Dry and Humid Atmosphere,” Dalton Trans., 44 10834-46 (2015).

${ }^{19}$ D. Han, K. Shinoda, S. Sato, M. Majima, and T. Uda, “Correlation between Electroconductive and Structural Properties of Proton Conductive Acceptor-Doped Barium Zirconate,” J. Mater. Chem. A., 3 [3] 1243-50 (2015).

${ }^{20}$ T. Schober, and H.G. Bohn, "Water Vapor Solubility and Electrochemical Characterization of the High Temperature Proton Conductor $\mathrm{BaZr}_{0.9} \mathrm{Y}_{0.1} \mathrm{O}_{2.95}$,” Solid State Ionics, 127 [3-4] 351-60 (2000).

${ }^{21}$ Imashuku, T. Uda, Y. Nose, G. Taniguchi, Y. Ito, and Y. Awakura, "Dependence of Dopant Cations on Microstructure and Proton Conductivity of Barium Zirconate,” J. Electrochem. Soc., 156 [1] B1-8 (2009).

${ }^{22}$ D. Han, Y. Okumura, Y. Nose, and T. Uda, "Synthesis of $\mathrm{La}_{1-x} \mathrm{Sr}_{x} \mathrm{Sc}_{1-y} \mathrm{Fe}_{y} \mathrm{O}_{3-\delta}$ (LSSF) and Measurement of Water Content in LSSF, LSCF and LSC Hydrated in Wet Artificial Air at 300 ${ }^{\circ}$ C,” Solid State Ionics, 181 [35] 1601-6 (2010). 
23 E. Fabbri, D. Pergolesi, S. Licoccia, and E. Traversa, "Does the Increase in Y-Dopant Concentration Improve the Proton Conductivity of $\mathrm{BaZr}_{1-x} \mathrm{Y}_{x} \mathrm{O}_{3-\delta}$ Fuel Cell Electrolytes?,” Solid State Ionics, 181 [21-22] 1043-51 (2010).

${ }^{24}$ Y. Ding, Y. Li, W. Deng, W. Huang, and C. Wang, "Variation of Optimum Yttrium Doping Concentrations of Perovskite Type Proton Conductors $\mathrm{BaZr}_{1-x} \mathrm{Y}_{x} \mathrm{O}_{3-\delta}(0 \leq x \leq 0.3)$ with Temperature,” J. Rare Earths, 31 [10] 1017-22 (2013).

${ }^{25}$ D. Han, K. Kishida, K. Shinoda, H. Inui, and T. Uda, “A Comprehensive Understanding of Structure and Site Occupancy of Y in Y-Doped BaZrO3,” J. Mater. Chem. A, 1 [9] 3027-33 (2013).

${ }^{26}$ K.D. Kreuer, St. Adams, W. Münch, A. Fuchs, U. Klock, and J. Maier, "Proton Conducting Alkaline Earth Zirconates and Titanates for High Drain Electrochemical Applications,” Solid State Ionics, 145 [1-4] 295-306 (2001).

${ }^{27}$ Y. Yamazaki, P. Babilo, and S.M. Haile, "Defect Chemistry of Yttrium-Doped Barium Zirconate: A Thermodynamic Analysis of Water Uptake,” Chem. Mater., 20 [20] 6352-7 (2008).

${ }^{28}$ H.G. Bohn, and T. Schober, "Electrical Conductivity of the High-Temperature Proton Conductor BaZr $0.9_{0.1} \mathrm{O}_{2.95}$, J J. Am. Ceram. Soc., 83 [4] 768-72 (2000).

Y. Yamazaki, R. Hernandez-Sanchez, and S.M. Haile, "Cation Non-stoichiometry in Yttrium-Doped Barium Zirconate: Phase Behavior, Microstructure, and Proton Conductivity,” J. Mater. Chem., 20 [37] 8158-66 (2010). 
30 B.C.H. Steele, and A. Heinzel, "Materials for Fuel-Cell Technologies,” Nature, 414 345-52 (2001).

${ }^{31}$ S. Imashuku, T. Uda, and Y. Awakura, "Sintering Properties of Trivalent Cation-Doped Barium Zirconate at $1600{ }^{\circ}$ C,” Electrochem. Solid-State Lett. 10[10] B175-9 (2007).

${ }^{32}$ S. Imashuku, T. Uda, Y. Nose, and Y. Awakura, "Fabrication and Electrical Characterization of 15\% Yttrium-Doped Barium Zirconate-Nitrate Freeze Drying Method Combined with Vacuum Heating,” J. Alloys Compd., 509 [9] 3872-9 (2011).

33 A.K. Azad, C. Savaniu, S. Tao, S. Duval, P. Holtappels, R.M. Ibberson, and J.T.S. Irvine, "Structural Origins of the Differing Grain Conductivity Values in $\mathrm{BaZr}_{0.9} \mathrm{Y}_{0.1} \mathrm{O}_{2.95}$ and Indication of Novel Approach to Counter Defect Association,” J. Mater. Chem., 18[29] 3414-8 (2008).

34 S.B.C. Duval, P. Holtappels, U.F. Vogt, U. Stimming, and T. Graule, "Characterization of $\mathrm{BaZr}_{0.9} \mathrm{Y}_{0.1} \mathrm{O}_{3-\delta}$ Prepared by Three Different Synthesis Methods: Study of the Sinterability and the Conductivity,” Fuel Cells, 9[5] 613-21 (2009).

${ }^{35}$ Y. Yamazaki, F. Blanc, Y. Okuyama, L. Buannic, J.C. Lucio-Vega, C.P. Grey, and S.M. Haile, “Proton Trapping in Yttrium-Doped Barium Zirconate,” Nature Mater., 12 647-51 (2013).

${ }^{36}$ I. Oikawa, and H. Takamura, "Correlation among Oxygen Vacancies, Protonic Defects, and the Acceptor Dopant in Sc-Doped $\mathrm{BaZrO}_{3}$ Studied by ${ }^{45}$ Sc Nuclear Magnetic Resonance,” Chem. Mater., 27 [19] 6660-7 (2015). 

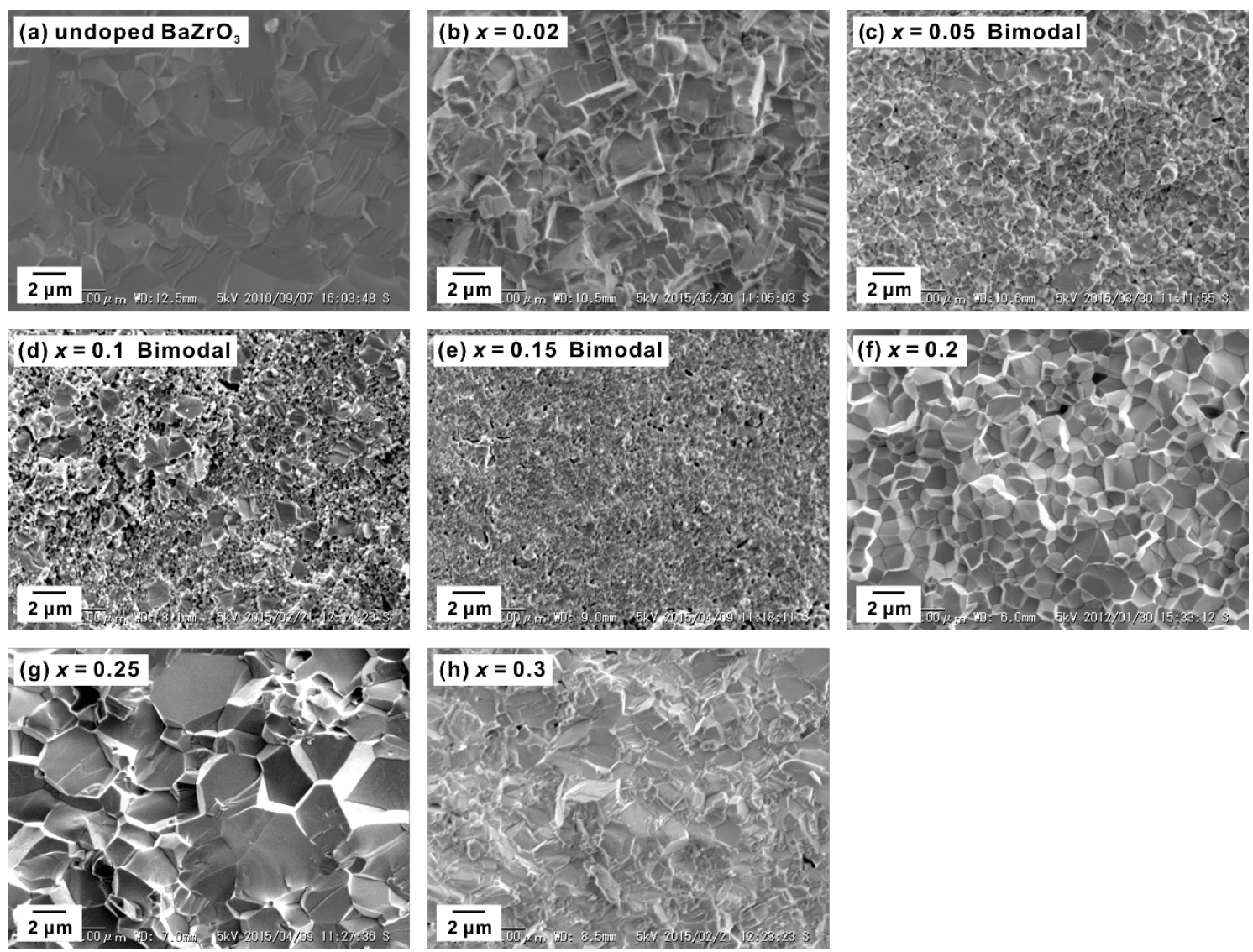

Fig. 1 SEM images of the fractured cross-section of undoped $\mathrm{BaZrO}_{3}$ and $\mathrm{BaZr}_{1-x} \mathrm{Y}_{x} \mathrm{O}_{3-\delta}(x=0.02$, 0.05, 0.1, 0.15, 0.2, 0.25 and 0.3). All the samples were heat-treated at $1600{ }^{\circ} \mathrm{C}$ in $\mathrm{O}_{2}$ for $24 \mathrm{~h}$ for sintering. 


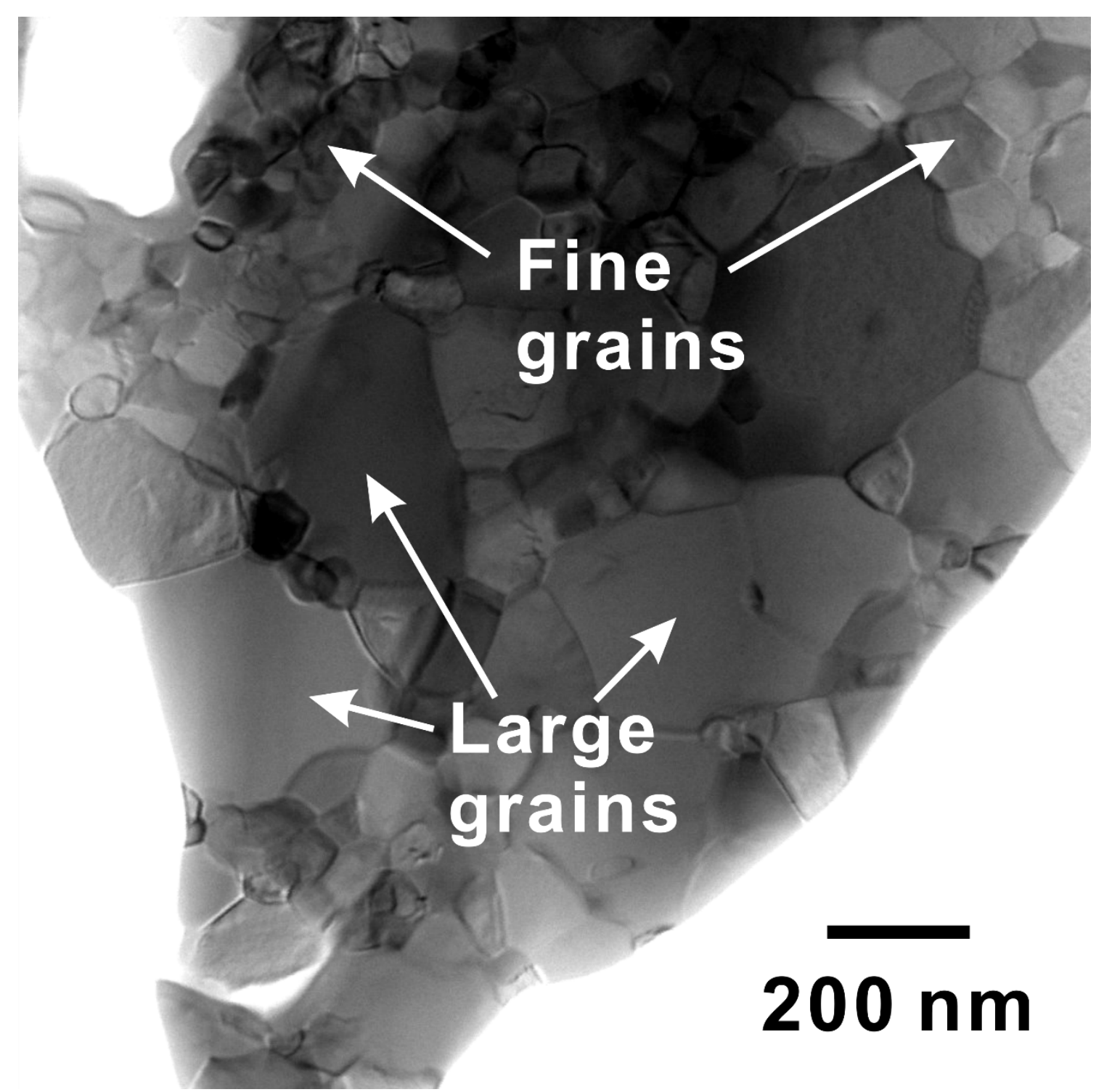

Fig. 2 A bright field STEM (BF-STEM) image of $\mathrm{BaZr}_{0.85} \mathrm{Y}_{0.15} \mathrm{O}_{3-\delta}(\mathrm{BZY} 15)$, in which a clear co-existence of large grains and fine grains can be seen. 
(a) Composition of large grains

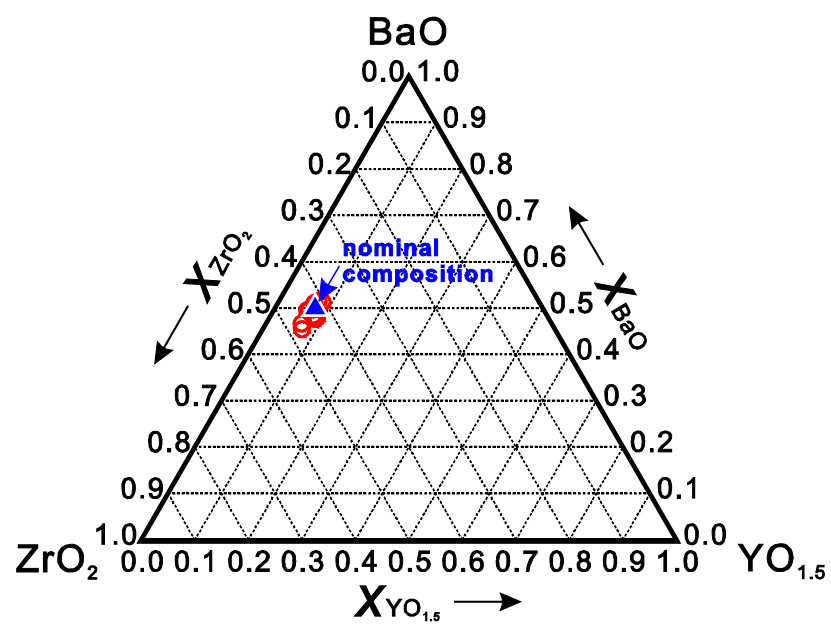

(b) Composition of fine grains

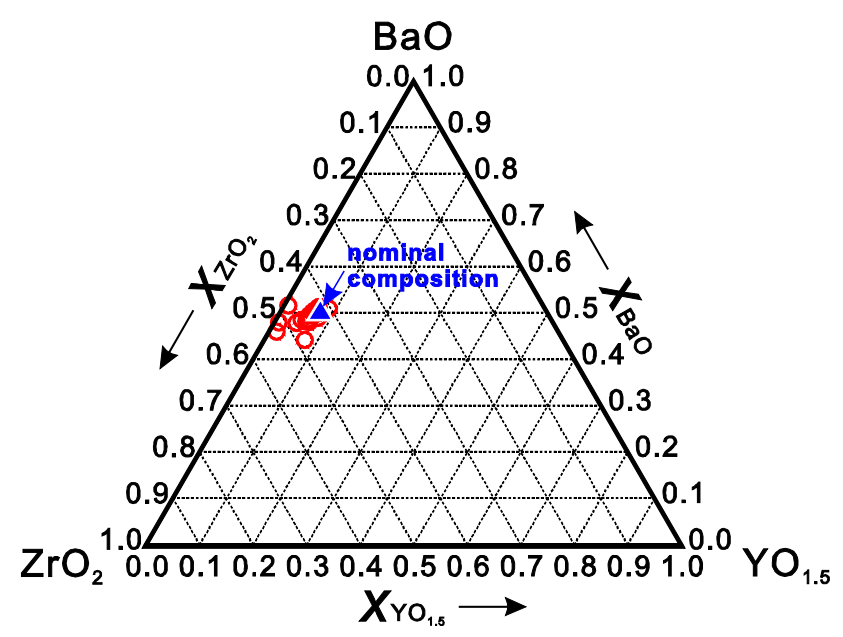

Fig. 3 Results of STEM-EDS point analysis of (a) large grains and (b) fine grains in $\mathrm{BaZr}_{0.85} \mathrm{Y}_{0.15} \mathrm{O}_{3-\delta}(\mathrm{BZY} 15)$. 


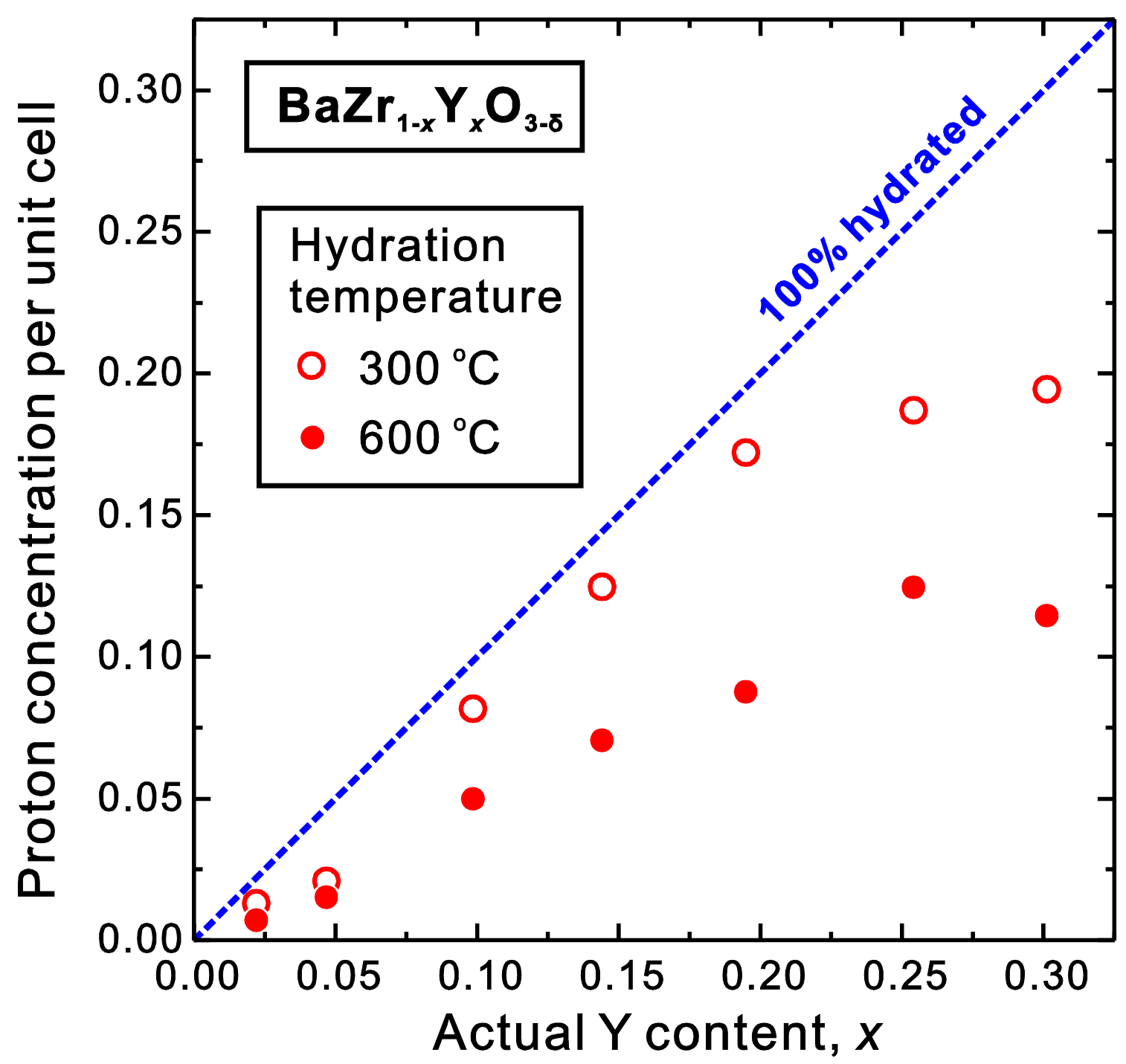

Fig. 4 Proton concentration of $\mathrm{BaZrO}_{3}$ doped with various $\mathrm{Y}$ content plotted against the actual Y content measured by ICP-AES. All the samples were sintered at $1600{ }^{\circ} \mathrm{C}$ in $\mathrm{O}_{2}$ for $24 \mathrm{~h}$, and hydrated at 300 or $600{ }^{\circ} \mathrm{C}$ in wet $\operatorname{Ar}\left(p_{\mathrm{H}_{2} \mathrm{O}}=0.05 \mathrm{~atm}\right)$. The proton concentration was calculated from the water content measured by Karl-Fischer titration method. The data of $\mathrm{BaZr}_{0.8} \mathrm{Y}_{0.2} \mathrm{O}_{3-\delta}$ are cited from our previous report [5]. 


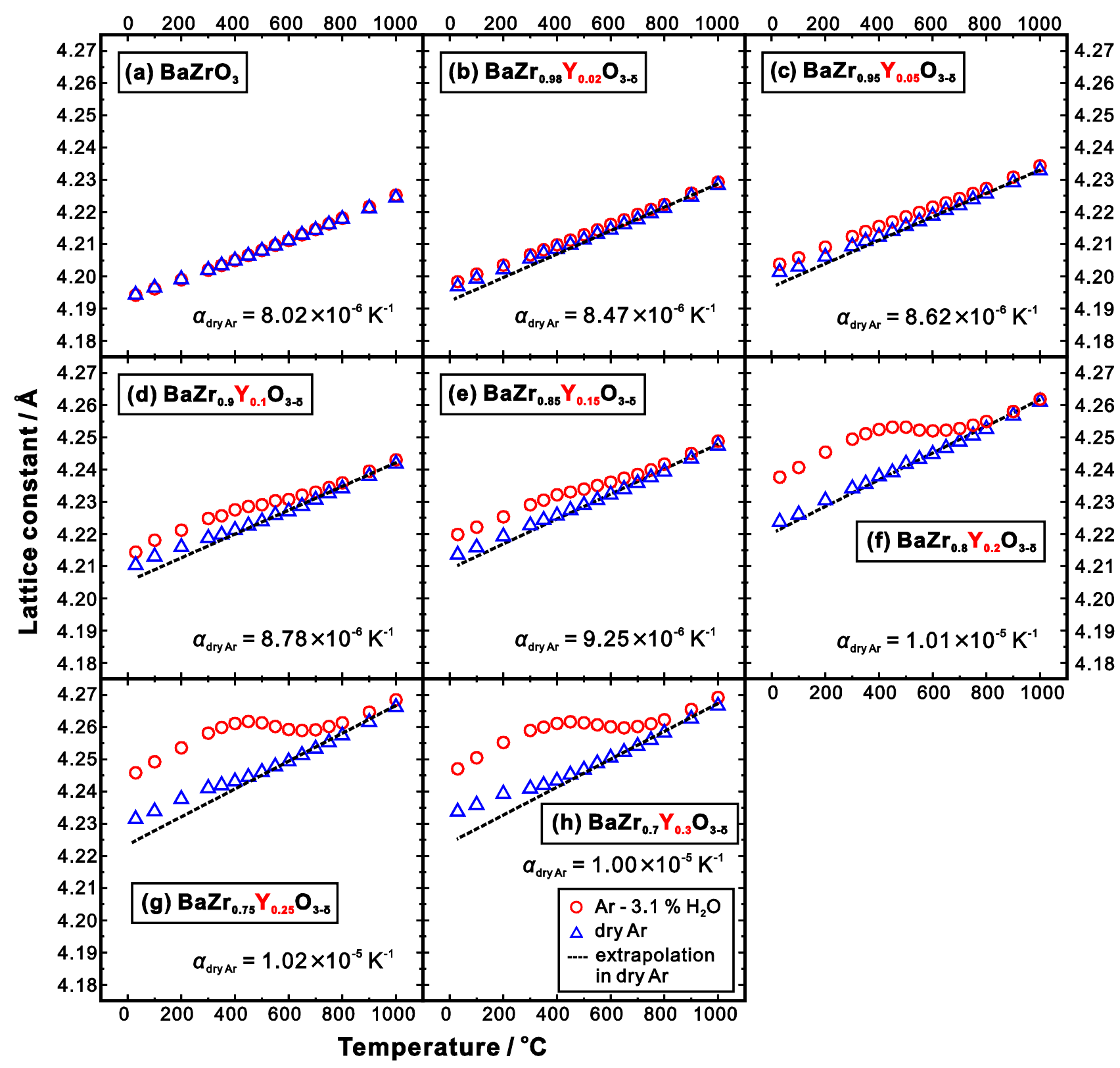

Fig. 5 Variation in lattice constants of undoped $\mathrm{BaZrO}_{3}$ and those doped with various $\mathrm{Y}$ content in dry Ar and wet $\operatorname{Ar}\left(p_{\mathrm{H}_{2} \mathrm{O}}=0.031 \mathrm{~atm}\right)$ with temperature. All the samples were finally heat-treated at $1600{ }^{\circ} \mathrm{C}$ in $\mathrm{O}_{2}$ for $24 \mathrm{~h}$ for sintering. 

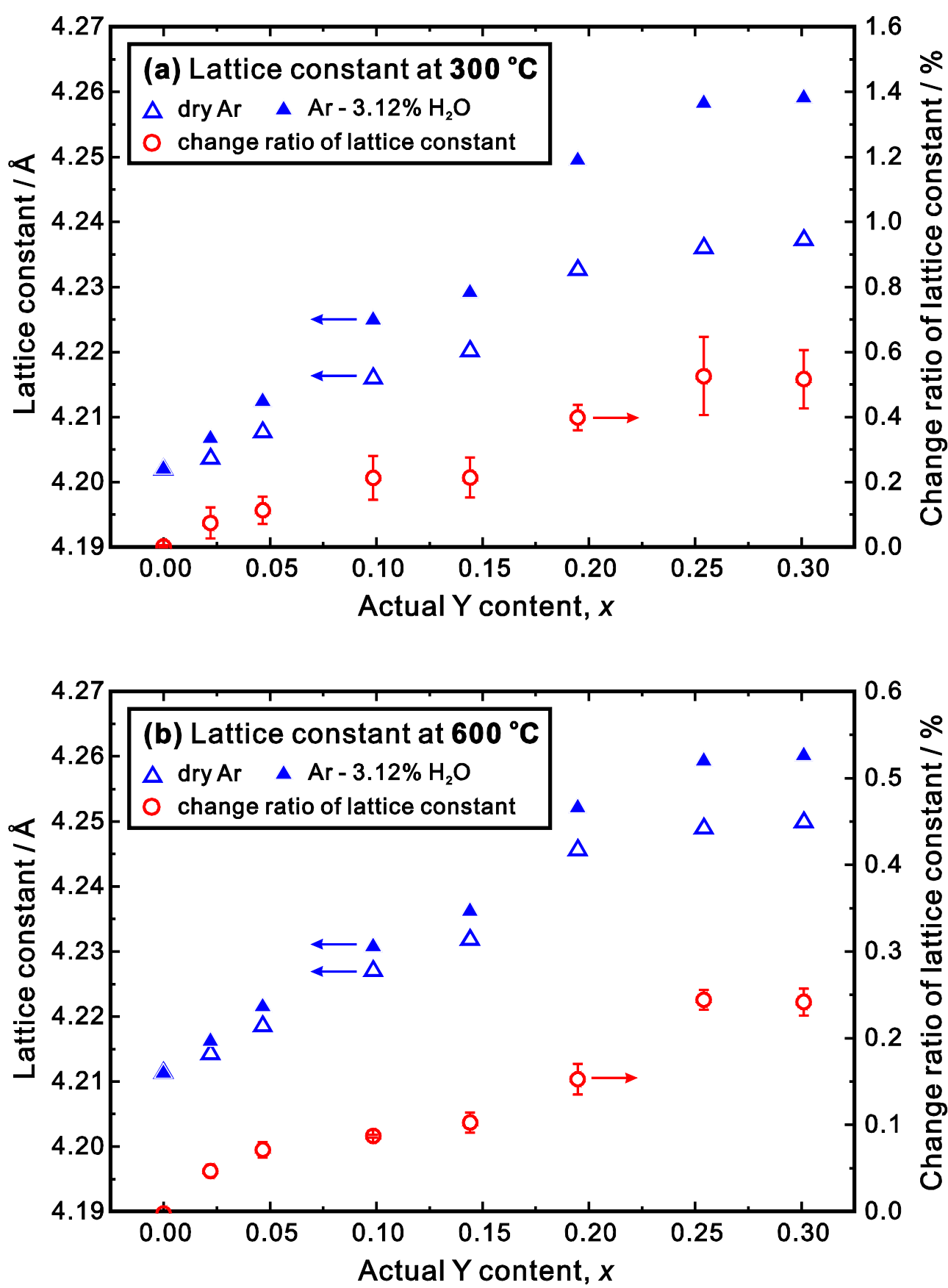

Fig. 6 Lattice constant of $\mathrm{BaZrO}_{3}$ doped with various $\mathrm{Y}$ content determined by $\mathrm{HT}-\mathrm{XRD}$ measurements in dry $\operatorname{Ar}$ and wet $\operatorname{Ar}\left(p_{\mathrm{H}_{2} \mathrm{O}}=0.031 \mathrm{~atm}\right)$ at (a) $300{ }^{\circ} \mathrm{C}$, and (b) $600{ }^{\circ} \mathrm{C}$ against the actual Y content determined by ICP-AES. The lattice constants in dry Ar were determined by extrapolating the data at high temperature range $\left(700-1000{ }^{\circ} \mathrm{C}\right)$. 

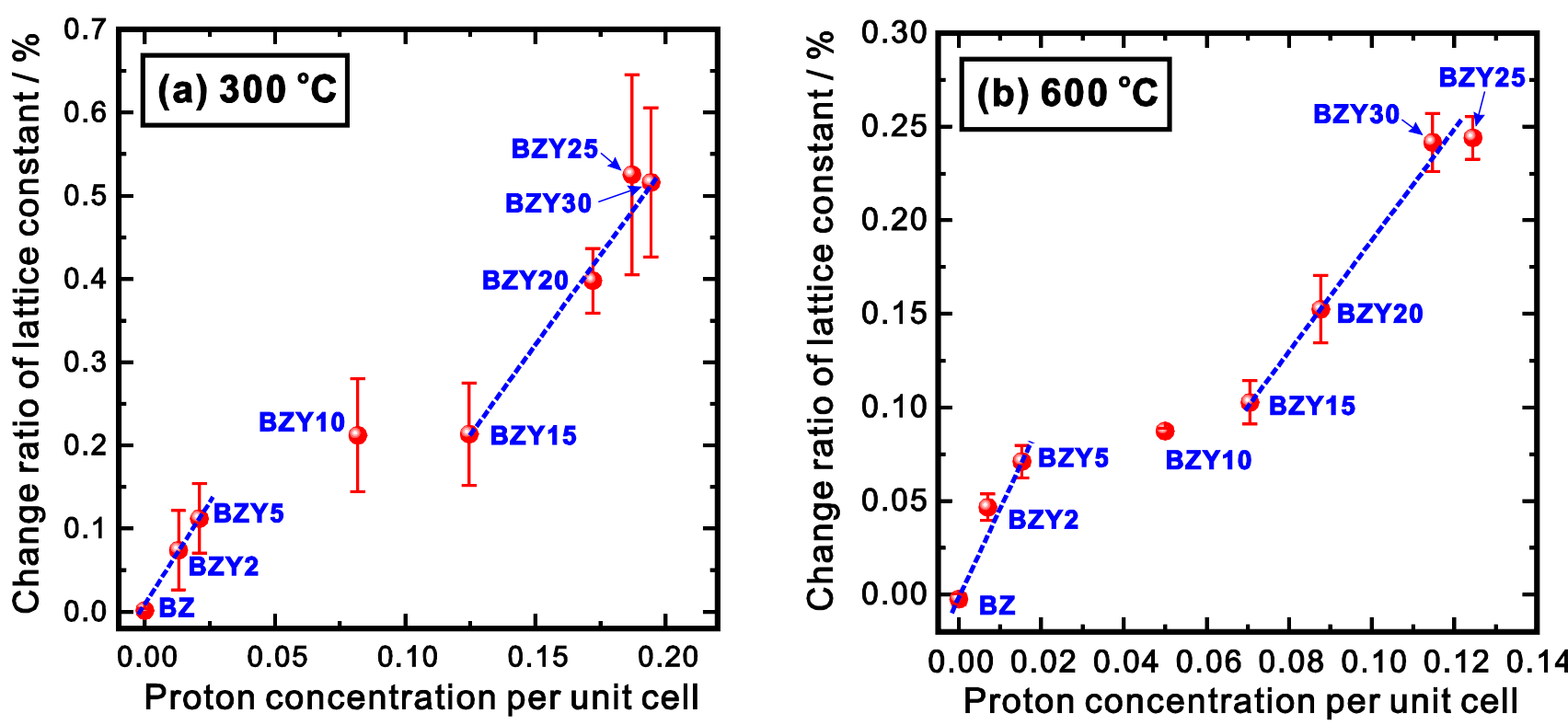

Fig. 7 Relationship between change ratio of lattice constant due to hydration and proton concentration per unit cell at (a) $300{ }^{\circ} \mathrm{C}$, and (b) $600{ }^{\circ} \mathrm{C}$. The proton concentration was measured by Karl-Fischer titration method on samples hydrated in wet $\mathrm{Ar}-5 \% \mathrm{H}_{2} \mathrm{O}$. The change ratio of lattice constant was calculated using the lattice constant determined by HT-XRD in dry $\mathrm{Ar}$ (extrapolated) and $\mathrm{Ar}-3.1 \% \mathrm{H}_{2} \mathrm{O}$. All the samples used here were sintered at $1600{ }^{\circ} \mathrm{C}$ in $\mathrm{O}_{2}$ for 24 h. 


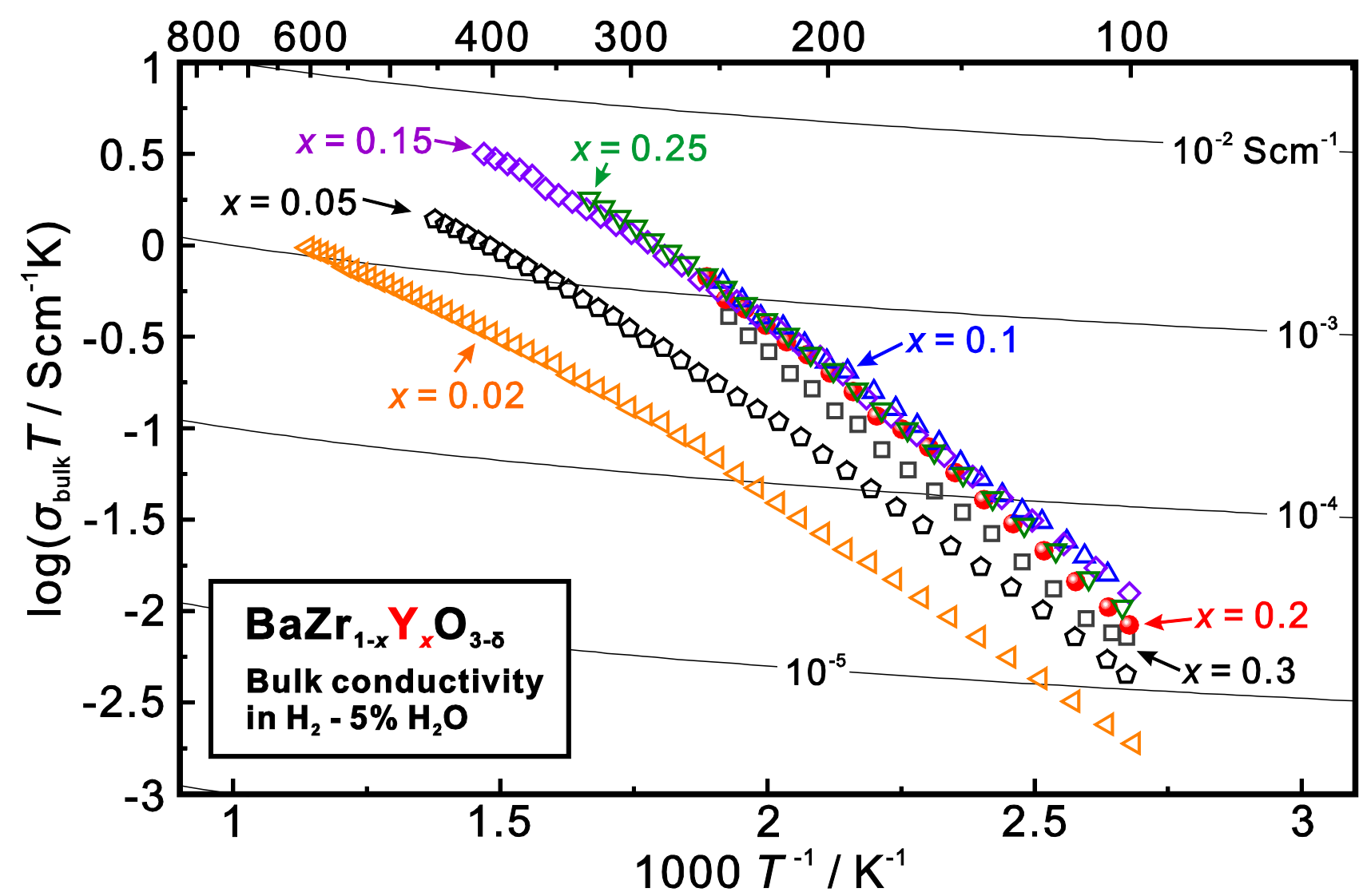

Fig. 8 Arrhenius plots of bulk conductivities of $\mathrm{BaZr}_{1-x} \mathrm{Y}_{x} \mathrm{O}_{3-\delta}(x=0.02,0.05,0.1,0.15,0.2,0.25$ and 0.3 ) in wet $\mathrm{H}_{2}$ atmosphere with the water vapor pressure of $0.05 \mathrm{~atm}$. All the samples were finally heat-treated at $1600{ }^{\circ} \mathrm{C}$ in $\mathrm{O}_{2}$ for $24 \mathrm{~h}$ for sintering. 


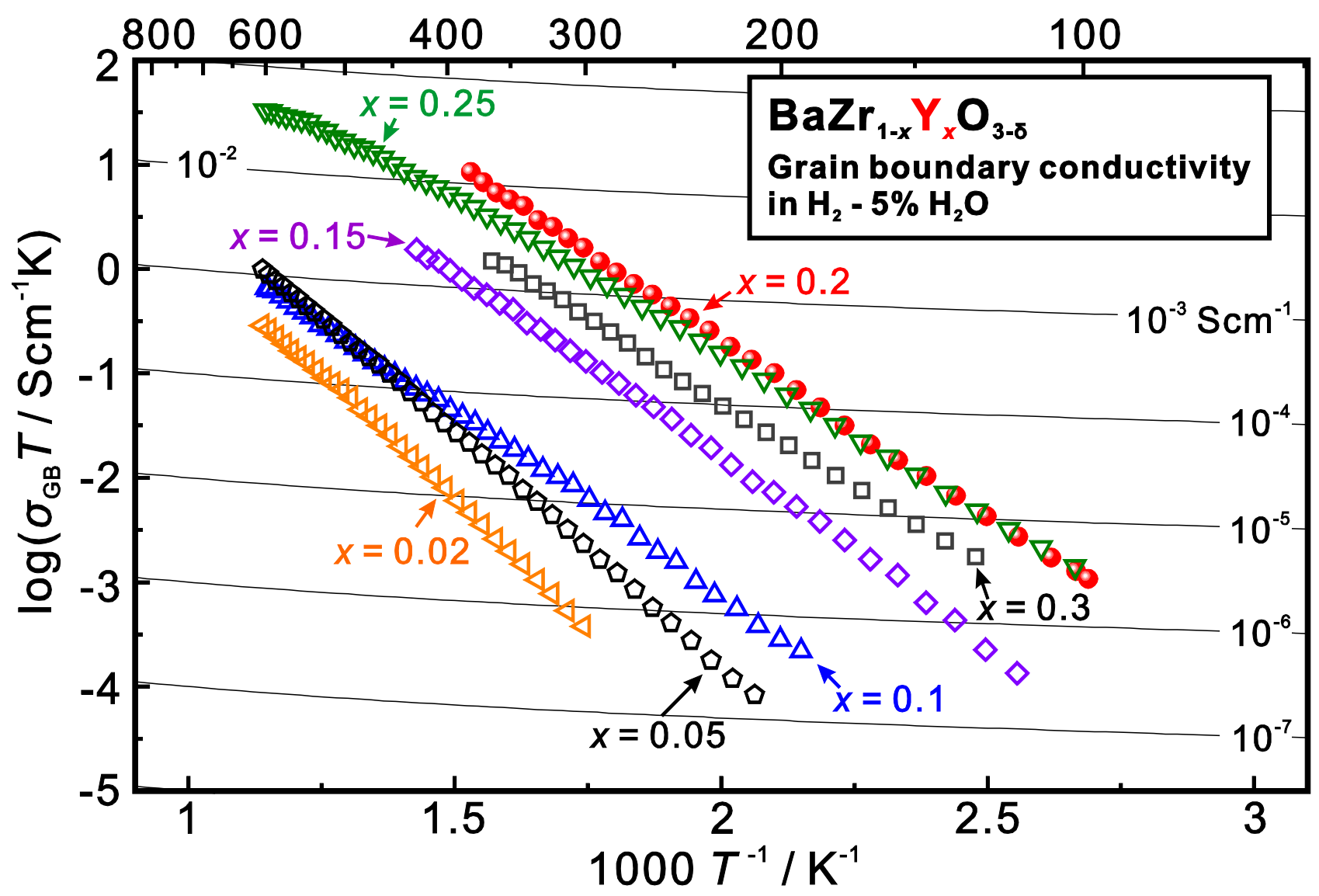

Fig. 9 Arrhenius plots of grain boundary conductivities of $\mathrm{BaZr}_{1-x} \mathrm{Y}_{x} \mathrm{O}_{3-\delta}(x=0.02,0.05,0.1,0.15$,

0.2, 0.25 and 0.3 ) in wet $\mathrm{H}_{2}$ atmosphere with the water vapor pressure of $0.05 \mathrm{~atm}$. All the samples were finally heat-treated at $1600{ }^{\circ} \mathrm{C}$ in $\mathrm{O}_{2}$ for $24 \mathrm{~h}$ for sintering. 


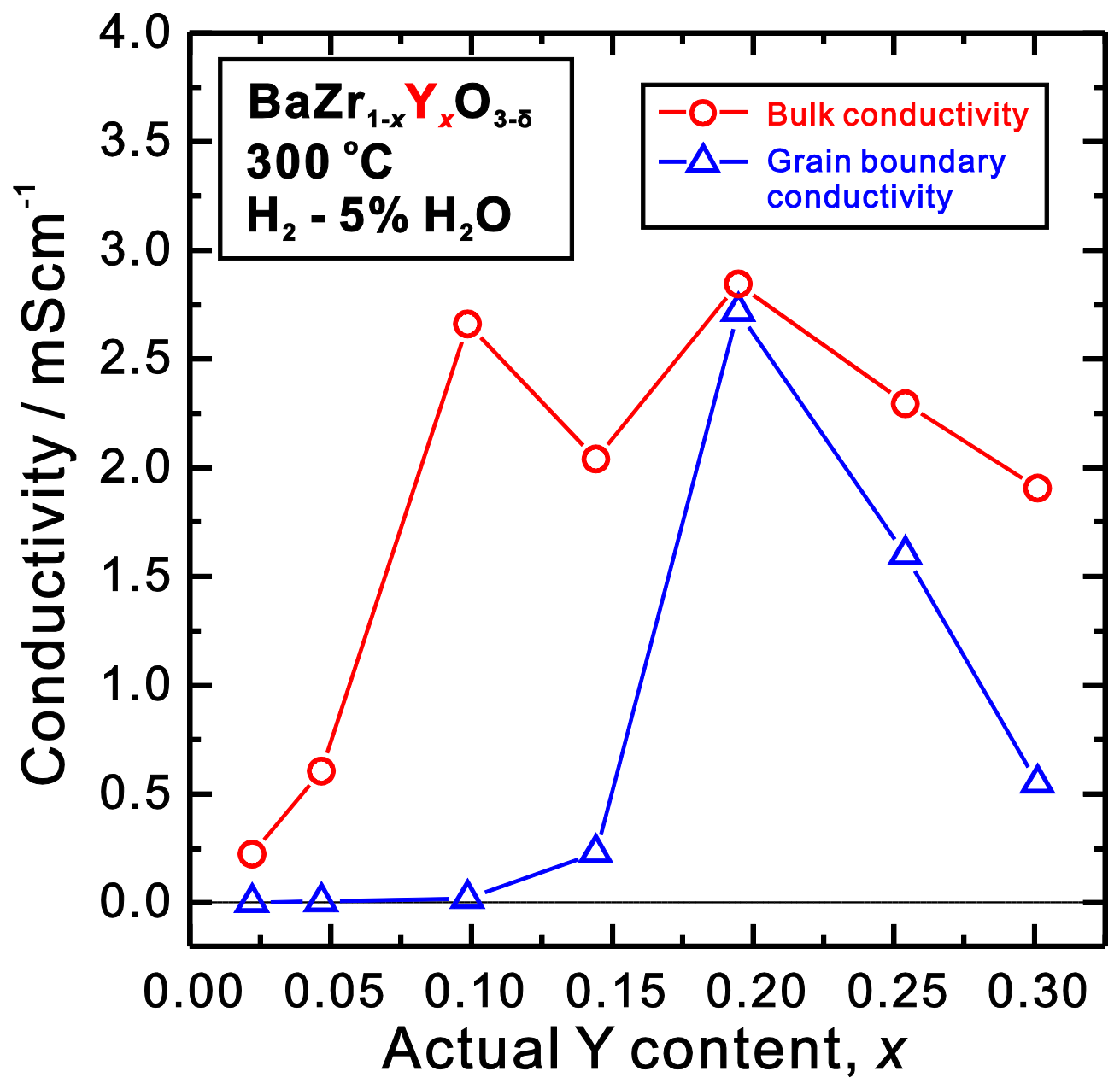

Fig. 10 Bulk conductivity and effective grain boundary conductivity of $\mathrm{BaZrO}_{3}$ doped with various $\mathrm{Y}$ content at $300{ }^{\circ} \mathrm{C}$ in wet $\mathrm{H}_{2}\left(p_{\mathrm{H}_{2} \mathrm{O}}=0.05 \mathrm{~atm}\right)$ plotted against the actual $\mathrm{Y}$ content determined by ICP-AES $\mathrm{H}_{2}-5 \% \mathrm{H}_{2} \mathrm{O}$ atmosphere. 

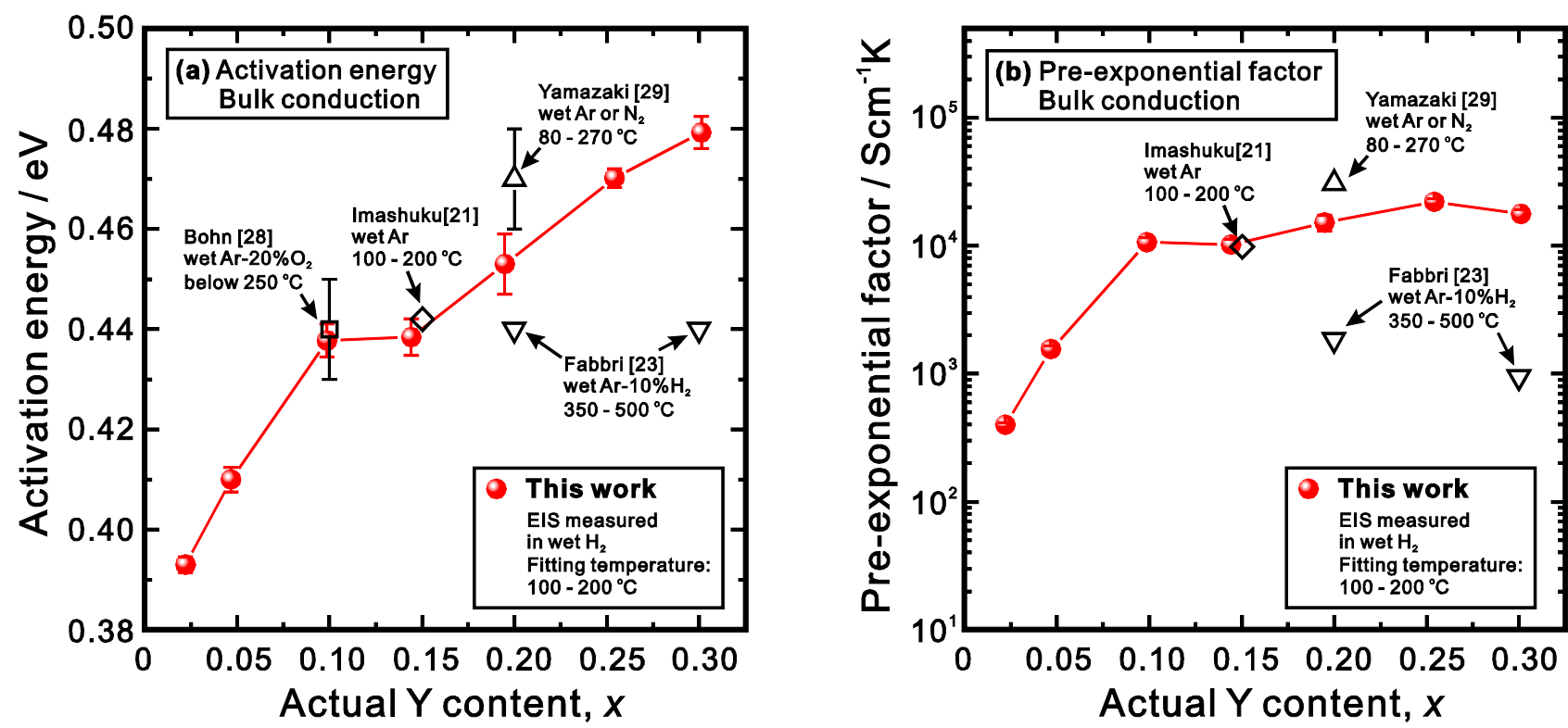

Fig. 11 (a) Activation energy and (b) pre-exponential factor of bulk conduction of $\mathrm{BaZrO}_{3}$ doped with various amount of $\mathrm{Y}$ plotted against the actual $\mathrm{Y}$ content determined by ICP-AES. The activation energy and pre-exponential factor were obtained by fitting the bulk conductivity measured in the temperature range around $100-200{ }^{\circ} \mathrm{C}$ in $\mathrm{H}_{2}-5 \% \mathrm{H}_{2} \mathrm{O}$ atmosphere. Literature data [21, 23, 28, 29] were also plotted for comparison. 


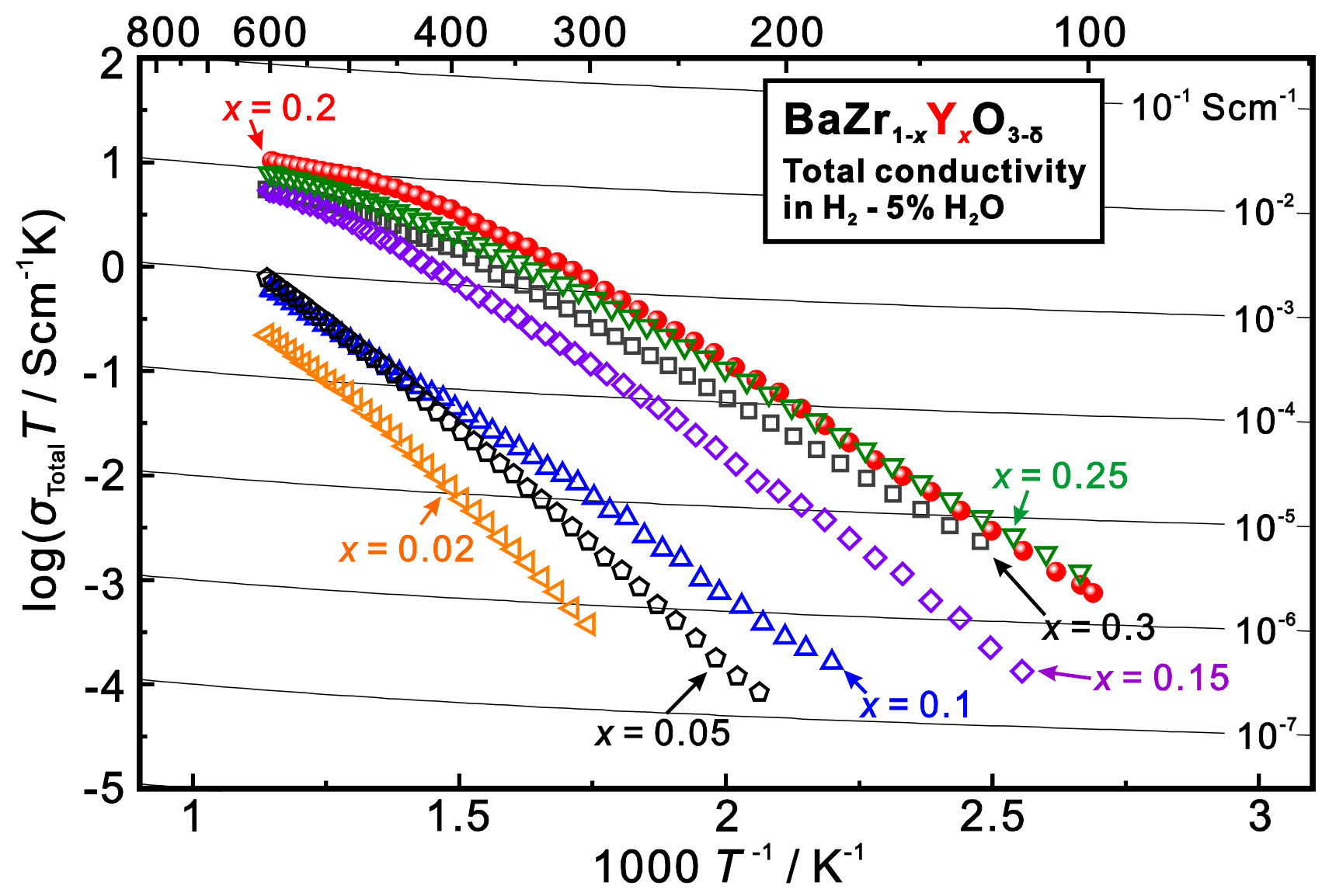

Fig. 12 Arrhenius plots of total conductivities of $\mathrm{BaZr}_{1-x} \mathrm{Y}_{x} \mathrm{O}_{3-\delta}(x=0.02,0.05,0.1,0.15,0.2,0.25$

and 0.3 ) in wet $\mathrm{H}_{2}$ atmosphere with the water vapor pressure of $0.05 \mathrm{~atm}$. All the samples were finally heat-treated at $1600{ }^{\circ} \mathrm{C}$ in $\mathrm{O}_{2}$ for $24 \mathrm{~h}$ for sintering. 


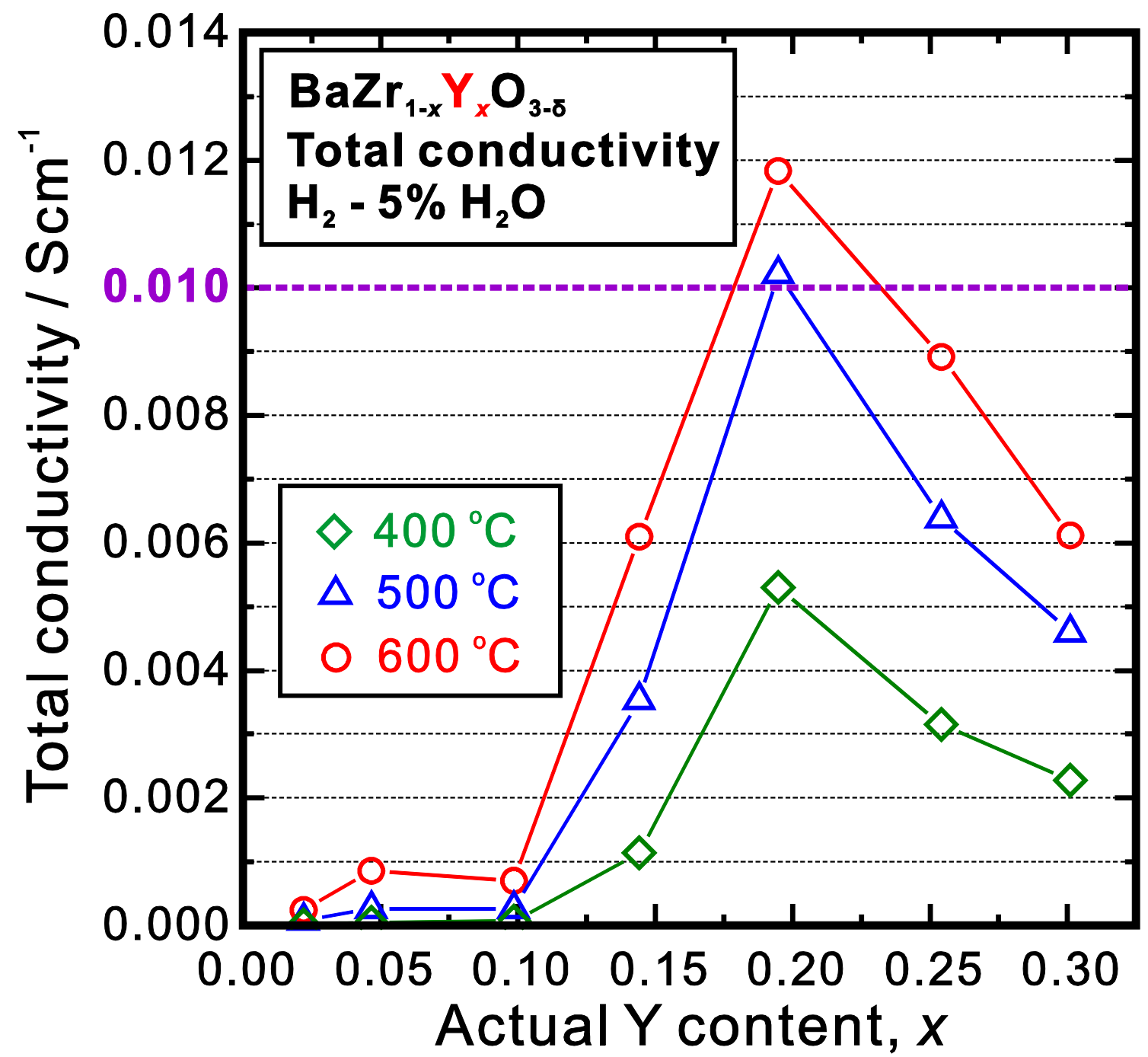

Fig. 13 Total conductivity of $\mathrm{BaZrO}_{3}$ doped with various $\mathrm{Y}$ content at 400, 500 and $600{ }^{\circ} \mathrm{C}$ in wet $\mathrm{H}_{2}\left(p_{\mathrm{H}_{2} \mathrm{O}}=0.05 \mathrm{~atm}\right)$ plotted against the actual Y content determined by ICP-AES. Violet dash line indicates the ionic conductivity of $0.01 \mathrm{Scm}^{-1}$ necessary for an applicable electrolyte in fuel cells. [30] 


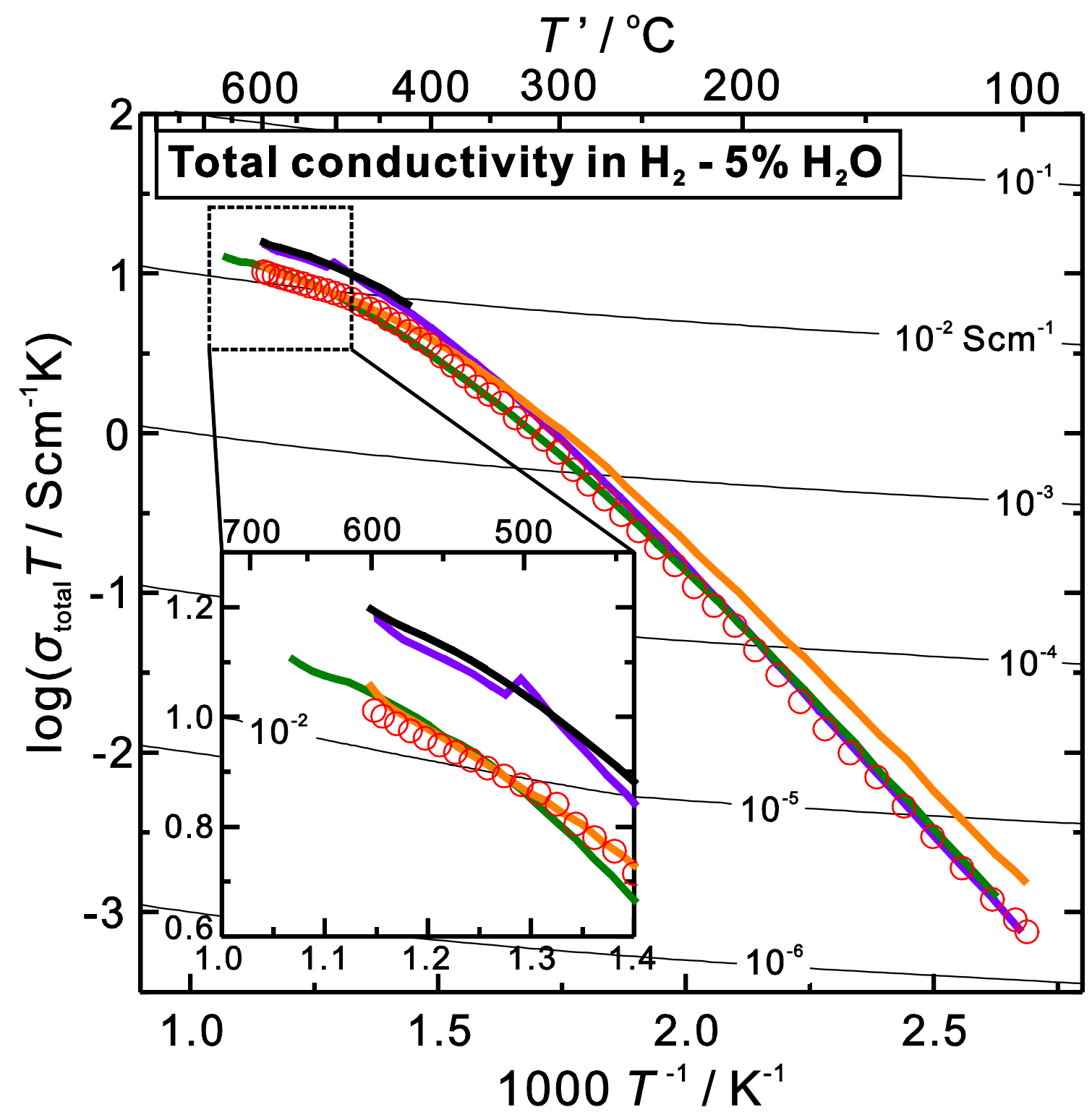

Fig. 14 Total conductivity in $\mathrm{H}_{2}-5 \% \mathrm{H}_{2} \mathrm{O}$ of $\mathrm{BaZr}_{0.8} \mathrm{Y}_{0.2} \mathrm{O}_{3-\delta}$ sintered at five different batches.

The data marked with circle symbols are those plotted in Fig. 12. 